\title{
Potential of Different Fungi Species in Biodegradation Field of Phenolic Compounds
}

\author{
Yassmin M. Shebany ${ }^{1,2^{*}}$, Eman G. El-Dawy ${ }^{1}$ and Youssuf A. Gherbawy ${ }^{1}$ \\ ${ }^{1}$ Department of Botany, Faculty of Science, South Valley University, Qena, Egypt. \\ ${ }^{2}$ Department of Biology, Faculty of Science, Taif University, Taif, Saudi Arabia.
}

\begin{abstract}
Authors' contributions
This work was carried out in collaboration among all authors. Author YMS designed the study, carried out practical experiments, wrote the protocol and wrote the first and final draft of the manuscript.

Author EGED performed the statistical analysis and some practical experiments and managed the literature searches. Author YAG wrote the first and final draft of the manuscript. All authors read and approved the final manuscript.

\section{Article Information}

DOI: $10.9734 / A R R B / 2018 / v 30 \mathrm{i} 430120$

Editor(s):

(1) Prof. George Perry,Dean and Professor of Biology, University of Texas at San Antonio, USA.

Reviewers:

(1) P. Saravana Kumari, Rathnavel Subramaniam College of Arts and Science, Sulur, Coimbatore, India.

(2) Dra Graciela Pucci, Universidad Nacional de la Patagonia San Juan Bosco, Argentina. Complete Peer review History: http://www.sdiarticle3.com/review-history/47494
\end{abstract}

Original Research Article

Received 27 October 2018

Accepted 10 February 2019

Published 07 March 2019

\begin{abstract}
Phenolic compounds are dominant pollutants in terrestrial and freshwater environmental that have toxic effects on living organisms at low concentrations, because it has the ability to persist in the ecosystem. So bio-removal is a good technique that employs the metabolic potential of microorganisms to clean up the environmental pollutants and turned into less dangerous or harmless substances. This work aims to the isolation of different species of fungi from wastewater of factories and Red Sea coast to test the ability of these fungi to degrade phenolic compounds. Ten species of fungi and sterile mycelium are used to degrade phenol and its derivatives at different concentrations $(0.4 \%, 0.6 \%$ and $0.8 \%)$. All fungi species have the ability of degradation of phenol and their derivatives, but $P$. chrysogenum, Saccharomyces sp. and sterile mycelium exhibited low ability to break down of hydroxyl-benzene, 2-naphthol and 1,3 dihydroxy benzene, respectively.
\end{abstract}

\footnotetext{
*Corresponding author: E-mail: yoyomsh@yahoo.com;
} 
Keywords: Biodegradation; phenolic compounds; fungi; chlorophyll pigment.

\section{INTRODUCTION}

Due to the release of phenolic compounds from agro-industrial operations, these compounds have become widespread in the world as environmental pollutants. Many of these aromatic compounds are toxic to the living system and their presence in the aquatic and terrestrial habitats often have serious ecological consequences, Where natural phenolic compounds are considered one of the most important and dangerous pollutants of the current environment [1]. Many industrial effluents and residues contain the structure of phenolic compound such as waste of ships, paper factories, aluminum factories, wine-distillery, olive oil extraction, green olive debittering, cork preparation, wood debarking, coffee production, coal gasification, coke-oven batteries, refinery and petrochemical plants and other industries that produce things such as synthetic chemicals, herbicides, pesticides, antioxidants, pulp-andpaper, photo developing chemicals, etc. [2-10].

These compounds are stable and even at low concentration they may be toxic towards living organisms and cause unfavorable chemical changes in water and soil as inhibiting the sunlight penetration and decrease the photosynthetic activity of aquatic system [11]. Phenolic compound is the most toxic and it can persist in the ecosystem for long time due to its long range transportation, bioaccumulation in human and animal tissue and bio-magnification in food chain [12]. Many serious diseases are caused by pollution phenol for both human and animal who inhalation and dermal contact such as cardiovascular diseases and severe skin damage, while ingestion can cause serious gastrointestinal damage and death. Even shortterm application of phenol to the skin can produce blisters and burns in animals [13]. For these reasons several physico-chemical methods are used to remediate phenolic wastes such as ozonisation, adsorption, reverse osmosis, electrolytic oxidation, photocatalysis [14]. While all these methods have failing, so some of these methods are very costly like ozonisation, electrochemical, reverse osmosis and photochemical, but the disadvantage of physical adsorption is the elimination of sludge [15], bioremediation by using microbial cells to resolve phenol contamination problem consider one of the cheapest possible solutions [16-19].
The oxidative activities of microorganisms are the principal reason for the biological treatment of industrial wastewaters. Filamentous fungi may be an important supply of phenol degrading species [20]. Fungi are known for their wide incidence and also the outstanding capability of degrading advanced and inert natural products such as lignin, chitin and cellulose. Fungi adopt additional simply than bacterium and are capable to grow in extreme conditions, like nutrient deficiency, low $\mathrm{pH}$, restricted water, etc. [21]. And not on the least, there comes the ability of fungi to survive within the presence of varied xenobiotics that turn to be toxic to variety of different microorganisms.

The purpose of this study was to investigate the ability of the different species of fungi to degrade some phenolic compounds, usually present in agro-industrial effluents and the effect of input and output degradation on chlorophyll pigments of chlorella sp.

\section{MATERIALS AND METHODS}

\subsection{Samples Collection}

Ten samples of wastewater were collected from different sites of Red Sea beach and factories in Upper Egypt during summer 2017. Wastewater samples were collected in sterile bottles $(100 \mathrm{ml})$ and in plastic bags, respectively, transferred directly to the laboratory and preserved at $4^{\circ} \mathrm{C}$ until used.

\subsection{Fungal Isolation and Identification}

Fungi were isolated from the wastewater collected from Red Sea beach and factories in Upper Egypt using Czapek-Dox salts medium. Water samples were suspended by vortexing and allowed to stand for several minutes. $1 \mathrm{ml}$ portion was plated onto the $\mathrm{Cz}$ media containing $12 \mathrm{mg} / \mathrm{mL}$ tetracycline and streptomycin solution respectively in order to suppress the growth of bacterial colonies then incubated at room temperature for 7 days. The sample was subcultured three times to obtain a pure culture, which was transferred to a $\mathrm{Cz}$ slant and stored at $4^{\circ} \mathrm{C}$ [22]. The most common fungi were recultivated using Czapek's Dox medium until pure colonies were obtained. These fungi were identified by microscope using the methods described by [23]. 


\subsection{Microorganisms}

Eighteen isolates belonged to 6 genus and 10 species (Alternaria alternate, Aspergillus flavus, A. fumgatius, $A$. niger, $A$. terreus, Cladosporium cladosporioides, penicillium aurantiogriseum, $P$. chrysogenum, Phoma sp., Saccharomyces sp. and sterile mycelium) were isolated from wastewater and used for degradation of phenol and its derivatives.

\subsection{Biodegradation Media}

Biodegradation was conducted on 4 combined media with 3 concentrations of phenol and their derivatives $(0.4 \%, 0.6 \%$ and $0.8 \%)$, containing the following ingredients as single carbon and energy sources: hydroxy benzene, 2-naphthol, 4nitrophenol and 1,3 dihydroxy benzene. The total concentration of phenolic compounds in each $100 \mathrm{ml}$ were $0.4 \%, 0.6 \%$ and $0.8 \%$. Media contained also Czapek-Dox salts (in \%), as follows: $\mathrm{NaNO} 3-0.2, \mathrm{KH} 2 \mathrm{PO} 4-0.1, \mathrm{KCl}-$ 0.05, MgSO4.7H2O - 0.05, FeSO4.7H2O 0.001 . The starting $\mathrm{pH}$ of culture media was 5.5 [24].

\subsection{Determination of Phenol Degradation Potential}

The isolates showing growth on Czapek-Dox salts were used for further studies on bioremediation of phenol. Ten $\mathrm{ml}$ Czapek-Dox salts broths were inoculated with a 8-d-old culture of the isolates, and the flasks were incubated under shake culture condition on a rotary shaker for 8 days at $28^{\circ} \mathrm{C}$. After an appropriate incubation period, the cells were removed by centrifugation and the cell-free supernatants were used for estimation of residual phenol. The residual phenol was estimated by [25].

\section{Folin -Ciocalteau reagent:}

The method employed the Folin - Ciocalteau phenol reagent (BDHL td) which was attended by the method of [26]. The general method involved the successive addition of $1.5 \mathrm{ml}$ sodium carbonate $\left(200 \mathrm{~g}^{-1}\right)$ and $0.5 \mathrm{ml}$ Folin-Ciocalteau phenol reagent to $10 \mathrm{ml}$ sample. After $60 \mathrm{~min}$ at $20^{\circ} \mathrm{C}$, the absorbance was measured at $725 \mathrm{~nm}$ against distilled water and correct for the absorbance of a distilled water reagent blank.

$$
\begin{aligned}
& \% \text { Phenol Removal Efficiency (PRE) } \\
& =\frac{\mathrm{Ci}-\mathrm{Cf}}{\mathrm{Ci}} \times 100
\end{aligned}
$$

Wherever, $\mathrm{Ci}$ is the initial concentration of phenol $(\mathrm{mg} / \mathrm{L})$ and $\mathrm{Cf}$ is the final concentration of phenol. All experiments of phenol biodegradation were done three times; the results were expresses as average \pm standard deviation (SD) [27].

\subsection{Biological Assay}

\subsubsection{Chorella sp. test}

Each extract of Aspergillus niger and Penicillium chrysogenum $(0.05 \mathrm{mg})$ was applied to $0.8 \mathrm{~cm}$ diameter filter paper disc (Whatman No.3), each disc was placed in test tube contained $10 \mathrm{ml}$ of Chorella sp. The tubes were kept at a temperature of $25 \pm 1^{\circ} \mathrm{C}$. A control tube with only Chorella sp. was also made, which incubated for 8 days.

\subsection{Determination of Pigments (Chlorophyll A, Chlorophyll B and Carotenoids)}

Pigment fractions were determined spectrocolorometrically according to [28]. A known volume $(10 \mathrm{ml})$ of Chorella $\mathrm{sp}$. suspension was centrifuged at $3000 \mathrm{rpm}$ and the growth medium was decanted. Pigments were extracted in hot methanol $\left(70^{\circ} \mathrm{C}\right)$ for 10 minutes. Cell debris was removed by centrifugation and the clear supernatant, which contains the pigments was aspirated and diluted to a definite volume. The extinction coefficient was measured using spectrophotometer (Spectronic 601) against a blank of methanol at the wavelengths of 452, 644 and $663 \mathrm{~nm}$. Taking into consideration the dilution made, the content of pigment fractions $(\mu \mathrm{g} / \mathrm{ml}$ algal suspension) were calculated using the following equations [29]:

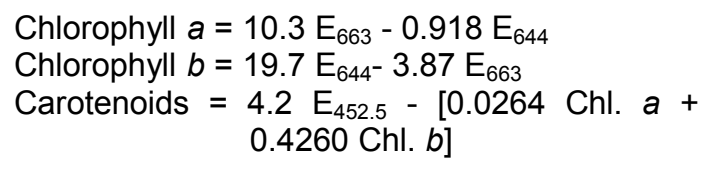

\subsection{Statistical Analysis}

The experimental data were subjected to multivariate analysis of variance using anova. Means were compared using Duncan's test at the $5 \%$ level using the SPSS program (SPSS Inc., Chicago, IL, USA). 


\section{RESULTS}

Ten species and sterile mycelium belonging to 6 genera were collected in the present study (Table 1). Aspergillus was represented by 4 species, and Penicillium was displayed by 2 species, while the other genera were introduced by one species. Saccharomyces was the common genus in this studies, which comprising $46.68 \%$ of total fungi and recovered from $20 \%$ of the total samples. Aspergillus ( $A$. flavus,
A. fumigatus, $A$. niger and $A$. terreus) followed by Saccharomyces sp., which contributed by $16.67 \%$ of total fungi and isolated from $40 \%$ of total samples. Penicillium ranked the third place in the count, which comprising $13.33 \%$ of total fungi. The remaining species (Alternaria alternate, Cladosporium cladosporioides, Phoma $\mathrm{sp}$. and sterile mycelium) were contributed collectively $23.33 \%$ of total fungi and isolated only from one sample.

Table 1. Total counts (TC, calculated per 30 colonies), percentage of fungal counts (\%C, calculated per total fungi) and frequency of fungal species (\%F, calculated per 10 samples) of various fungal genera and species recovered from 10 samples of wastewater

\begin{tabular}{lllll}
\hline Genera and species & TC & C\% & NCl & F\% \\
\hline Alternaria alternate & 3 & 10.00 & 1 & 10 \\
Aspergillus & 5 & 16.67 & 4 & 40 \\
A. flavus Link & 1 & 3.33 & 1 & 10 \\
A. fumigatus Fresenius & 1 & 3.33 & 1 & 10 \\
A. niger Van Teighem & 2 & 6.67 & 2 & 20 \\
A. terreus var. africanus Fennell and & 1 & 3.33 & 1 & 10 \\
Raper & & 6.67 & 1 & 10 \\
Cladosporium cladosporioides (Fres.) & 2 & & & \\
de Vries & & 13.33 & 2 & 20 \\
Penicillium & 4 & 10.00 & 2 & 20 \\
P. aurantiogriseum Dierckx & 3 & 3.33 & 1 & 10 \\
P. chrysogenum Thom & 1 & 3.33 & 1 & 10 \\
Phoma sp. & 1 & 46.68 & 2 & 20 \\
Saccharomyces sp. & 14 & 3.33 & 1 & 10 \\
Sterile mycelium & 1 & $\mathbf{1 0 0 . 0 0}$ & & \\
\hline Total Account & $\mathbf{3 0}$ & & & \\
\hline
\end{tabular}

Table 2. Potency of different species of fungi on degradation of phenol derivatives at $0.4 \%$ concentrations, incubated at $28^{\circ} \mathrm{C}$ for 8 days

\begin{tabular}{lllll}
\hline Species & \multicolumn{4}{c}{$\begin{array}{c}\text { Degradation (\%) of phenol derivatives at } \mathbf{0 . 4 \%} \\
\text { concentrations }\end{array}$} \\
\cline { 2 - 5 } & $\begin{array}{l}\text { Hydroxy- } \\
\text { benzene }\end{array}$ & 2-Naphthol & 4-Nitrophenol & $\begin{array}{l}\text { 1,3Dihydroxy } \\
\text { benzene }\end{array}$ \\
\hline Alternaria alternate & $85.37^{*}$ & $46.02^{*}$ & $40.23^{*}$ & $84.37^{*}$ \\
A. flavus Link & $85.57^{*}$ & $33.88^{*}$ & $38.31^{*}$ & $87.08^{*}$ \\
A. fumigatus Fresenius & $83.11^{*}$ & $37.88^{*}$ & $54.46^{*}$ & $88.02^{*}$ \\
A. niger Van Teighem & $82.10^{*}$ & $19.33^{*}$ & $37.97^{*}$ & $84.08^{*}$ \\
A. terreus var. africanus & $87.68^{*}$ & $31.07^{*}$ & $42.49^{*}$ & $87.29^{*}$ \\
Cladosporium cladosporioides & $87.97^{*}$ & $30.58^{*}$ & $48.59^{*}$ & $90.40^{*}$ \\
P. aurantiogriseum Dierckx & $84.26^{*}$ & $39.26^{*}$ & $38.53^{*}$ & $87.81^{*}$ \\
P. chrysogenum Thom & $2.2^{*}$ & $31.96^{*}$ & $50.51^{*}$ & $87.23^{*}$ \\
Phoma sp. & $88.05^{*}$ & $41.37^{*}$ & $43.50^{*}$ & $88.20^{*}$ \\
Saccharomyces sp. & $83.94^{*}$ & $30.44^{*}$ & $16.05^{*}$ & $86.65^{*}$ \\
Sterile mycelium & $87.38^{*}$ & $27.14^{*}$ & $54.80^{*}$ & $1.01^{*}$ \\
\hline
\end{tabular}

*. The mean difference is significant at the 0.05 level 
Table 3. Potency of different species of fungi on degradation of phenol derivatives at $0.6 \%$ concentrations, incubated at $28^{\circ} \mathrm{C}$ for 8 days

\begin{tabular}{lllll}
\hline \multirow{2}{*}{ Species } & \multicolumn{4}{l}{ Degradation (\%) of phenol derivaties at 0.6\% concentrations } \\
\cline { 2 - 5 } & $\begin{array}{l}\text { Hydroxy- } \\
\text { benzene }\end{array}$ & 2-Naphthol & 4-Nitrophenol & $\begin{array}{l}\text { 1,3Dihydroxy } \\
\text { benzene }\end{array}$ \\
\hline Alternaria alternate & $81.87^{*}$ & $30.61^{*}$ & $37.72^{*}$ & $81.98^{*}$ \\
A. flavus Link & $83.21^{*}$ & $21.55^{*}$ & $73.70^{*}$ & $87.08^{*}$ \\
A. fumigatus Fresenius & $82.20^{*}$ & $29.59^{*}$ & $77.36^{*}$ & $84.55^{*}$ \\
A. niger Van Teighem & $82.21^{*}$ & $44.43^{*}$ & $15.32^{*}$ & $80.52^{*}$ \\
A. terreus var. africanus & $81.87^{*}$ & $29.34^{*}$ & $37.62^{*}$ & $67.80^{*}$ \\
Cladosporium cladosporioides & $83.51^{*}$ & $50.09^{*}$ & $72.03^{*}$ & $86.47^{*}$ \\
P. aurantiogriseum Dierckx & $81.69^{*}$ & $34.41^{*}$ & $81.02^{*}$ & $86.29^{*}$ \\
P. chrysogenum Thom & $26.40^{*}$ & $20.79^{*}$ & $59.38^{*}$ & $85.51^{*}$ \\
Phoma sp. & $83.19^{*}$ & $30.50^{*}$ & $76.80^{*}$ & $72.59^{*}$ \\
Saccharomyces sp. & $67.88^{*}$ & $1.1^{*}$ & $50.06^{*}$ & $84.21^{*}$ \\
Sterile mycelium & $83.86^{*}$ & $38.10^{*}$ & $33.96^{*}$ & $82.55^{*}$ \\
\hline \multicolumn{4}{l}{}
\end{tabular}

Table 2 explained the Effect of different species of fungi on degradation of phenol derivatives at $0.4 \%$ concentrations, so the results showed that the ability of different fungi species on biodegradation of phenol derivatives were differed according to the type of phenol derivatives, so hydroxy-benzene and 1,3 dihydroxy benzene exhibited the highest biodegradation by fungi species, but 2-Naphthol and 4-Nitrophenol showed the moderate bioremoval by fungi species. The highest degradation of 1,3 dihydroxy benzene was done by Cladosporium cladosporioides (90.40 \%). While the lowest bio-removal occurred by sterile mycelium for 1,3 dihydroxy benzene (1.01\%).

In general, Table 3 showed that the ability of fungi species to degrade the phenol derivatives at $0.6 \%$ concentrations, so all species of fungi exhibited the degradation of phenol compounds by different proportions. Fungi species degrade phenol derivatives in range between 1.1 to 87.08 $\%)$. A. flavus appeared highest ability for analysis of 1,3dihydroxy benzene compound (87.08), while Saccharomyces sp. showed lowest degradation of 2-Naphthol compound (1.1\%).

Table 4 appeared the potency of different species of fungi on degradation of phenol compounds, where the ability of degradation of phenol and their derivatives increased with increased the concentration of phenol based on the results detected in many species of fungi. All species exhibited the potency to degrade phenol and their derivatives, but the potency differed from species to species, and from derivatives to derivatives. So Cladosporium cladosporioides showed the highest degradation of hydroxyl benzene $(95.00 \%)$, while sterile mycelium appeared the lowest degradation of 1,3dihydroxy benzene (1.59\%).

In this study, we choose two species of degraded fungi of phenol and their derivatives ( $A$. niger and $P$. chrysogenum) at different concentration of phenol to find out the ability of input and output of phenolic compounds degradation on photosynthetic pigments of chlorella $\mathrm{sp}$. (Table 5). Furthermore the value of chlorophyll pigments was increased under output effects of phenolic compounds degradation than input bioremoval. The results in Table 5 explained that the highest value of chlorophyll was showed at concentration $0.8 \%$ of 2-naphthol which degrade by $P$. chrysogenum (12.83 $\mathrm{mg} / \mathrm{g}$ fresh wt.), followed by concentration $0.8 \%$ of hydroxylbenzene which removal by $A$. niger $(12.05 \mathrm{mg} / \mathrm{g}$ fresh wt.). While low value of photosynthetic pigments of chlorella sp. was observed at concentration $0.4 \%$ for control sample $(3.75 \mathrm{mg} / \mathrm{g}$ fresh wt.).

\section{DISCUSSION}

The ability of microorganisms to eliminate injurious chemicals from contaminated environments powerfully depends on the presence of different compounds. Most industrial wastes embrace totally different organic mixtures creating vital the investigation on the microbic destruction of composite substrates. The bioremoval or degradation of one or all elements are often delayed and/or discontinued depending on the composition of the studied mixture. 
Wastewaters from oil refineries, mining business and variety of industrial chemical syntheses contain several aromatics as phenol, cresols, nitrophenols, etc. [30]. The metabolism of aromatic compounds, notably phenol and their derivatives explained in prokaryotic microorganisms [31,32]. Ten species and sterile mycelium belonging to 6 genera were collected in the present study. Aspergillus was represented by 4 species, and Penicillium was displayed by 2 species, while the other genera were introduced by one species. Aspergillus, Penicillium and Neurospora attack aromatics and a variety of soil and wood-rotting fungi dissimilate the aromatic polymer lignin, as well as other plant phenolics [33]. Another fungus, the Penicillium strain $\mathrm{Bi} 7 / 2$ has been shown the ability of growth on phenolic compounds as sole source of carbon and energy, including protocatechuic and gallic acids [34].

Aspergillus ( $A$. flavus, $A$. fumigatus, $A$. niger and A. terreus) was followed Saccharomyces sp., which contributed by $16.67 \%$ of total fungi and isolated from $40 \%$ of total samples. Three species of fungi $(H$. bergeri, $F$. oxysporum and $A$. flavus var. coulmnaris) were the most common fungal species from the 25 samples of soils collected from the three Governorates (EI Gharbia, Kafre El Sheikh and El-Menofia) [13].

From results in Tables (2, 3 and 4), we have a tendency to showed that every one fungal species used have the ability to degrad the phenol and their derivatives. The microorganisms have the flexibility of removing phenol depended on the action of sort of enzymes. In bio-removal of phenol under aerobic conditions, the degradation is started by oxygenation in which the aromatic ring is initially monohydroxylated by a mono oxygenase phenol hydroxylase at a position ortho to the pre-existing radical to compose catechol. Catechol is that the main intermediate ensuing from metabolism of phenol by completely different microbic strains. Betting on the sort of strain, the catechol then undergoes a ring break down which will occur either at the ortho position so initiating the ortho pathway that results in the formation of succinyl Co-A and ethanoyl radical Co-A or at the meta position so initiating the meta pathway that results in the formation of pyruvate and acetaldehyde ${ }^{1}$. The results obtained from this investigation explained that, in generally the ability of different species of fungi for degradation of hydroxyl-benzene, 2naphthol and 4-nitrophenol increased with increasing the concentration of phenol and their derivatives. A lot of fungi species have ability to degrade phenol. Consequently, two species of fungi ( Mucor sp. and Rhizopus sp. ) have the ability with highest degardation of phenole at initial concentration $100 \mathrm{mg} / \mathrm{l}$. There is a relationship between the ability of fungi to analyze phenol with its concentration [27]. Many species of fungi produce extracellular enzymes for the metabolism complex carbohydrates into simple carbohydrates used by fungi as a source of sugar, for this reason, it has become possible to degrade pollutants such as phenol [35].

Table 4. Potency of different species of fungi on degradation of phenol derivatives at $0.8 \%$ concentrations, incubated at $28^{\circ} \mathrm{C}$ for 8 days

\begin{tabular}{lllll}
\hline Species & \multicolumn{3}{l}{ Degradation (\%) of phenol derivaties at $\mathbf{0 . 8 \%}$ concentrations } \\
\cline { 2 - 5 } & $\begin{array}{l}\text { Hydroxy- } \\
\text { benzene }\end{array}$ & 2-naphthol & 4-nitrophenol & $\begin{array}{l}\mathbf{1 , 3} \text { dihydroxy } \\
\text { benzene }\end{array}$ \\
\hline Alternaria alternate & $89.27^{*}$ & $35.33^{*}$ & $67.52^{*}$ & $75.82^{*}$ \\
A. flavus Link & $94.60^{*}$ & $29.90^{*}$ & $51.50^{*}$ & $83.82^{*}$ \\
A. fumigatus Fresenius & $90.27^{*}$ & $25.43^{*}$ & $57.52^{*}$ & $89.11^{*}$ \\
A. niger Van Teighem & $66.71^{*}$ & $24.75^{*}$ & $8.05^{*}$ & $65.41^{*}$ \\
A. terreus var. africanus & $79.59^{*}$ & $30.10^{*}$ & $5.58^{*}$ & $59.10^{*}$ \\
Cladosporium cladosporioides & $95.00^{*}$ & $37.79^{*}$ & $56.64^{*}$ & $89.94^{*}$ \\
P. aurantiogriseum Dierckx & $93.17^{*}$ & $32.79^{*}$ & $54.87^{*}$ & $91.26^{*}$ \\
P. chrysogenum Thom & $26.74^{*}$ & $34.14^{*}$ & $45.84^{*}$ & $86.53^{*}$ \\
Phoma sp. & $81.71^{*}$ & $22.55^{*}$ & $60.00^{*}$ & $24.54^{*}$ \\
Saccharomyces sp. & $72.88^{*}$ & $32.85^{*}$ & $46.37^{*}$ & $88.42^{*}$ \\
Sterile mycelium & $93.67^{*}$ & $31.33^{*}$ & $46.90^{*}$ & $1.59^{*}$ \\
\hline \multicolumn{4}{l}{}
\end{tabular}


Table 5. Concentrations of photosynthetic pigments of chlorella sp. (mg/g fresh wt) under effect of input and output of phenolic compounds degradation at different concentrations by $A$. niger and $P$. chrysogenum

\begin{tabular}{lllll}
\hline $\begin{array}{l}\text { Phenol } \\
\text { derivatives }\end{array}$ & Concentrations & \multicolumn{3}{c}{ Treatments } \\
\cline { 2 - 5 } & & Control & A. niger & P. chrysogenum \\
\hline Hydroxy-benzene & 0.4 & $4.65 \pm 0.14$ & $6.77^{*} \pm 0.23$ & $5.53^{*} \pm 0.10$ \\
& 0.6 & $5.00 \pm 0.00$ & $5.87^{*} \pm 0.04$ & $7.64^{\star} \pm 0.22$ \\
2-Naphthol & 0.8 & $5.34 \pm 0.06$ & $12.05^{*} \pm .0 .15$ & $10.23^{*} \pm 0.07$ \\
& 0.4 & $4.87 \pm 0.22$ & $4.64 \pm 0.07$ & $4.86 \pm 0.15$ \\
& 0.6 & $5.94 \pm 0.26$ & $7.47^{*} \pm 0.14$ & $6.49^{*} \pm 0.066$ \\
4-Nitrophenol & 0.8 & $3.84 \pm 0.11$ & $9.14^{\star} \pm 0.04$ & $12.83^{*} \pm 0.22$ \\
& 0.4 & $3.75 \pm 0.08$ & $4.09^{*} \pm 0.04$ & $4.35^{\star} \pm 0.08$ \\
1,3Dihydroxy & 0.6 & $6.84 \pm 0.051$ & $5.62^{*} \pm 0.04$ & $6.81 \pm 0.12$ \\
benzene & 0.8 & $6.25 \pm 0.10$ & $6.87^{*} \pm 0.13$ & $8.64^{*} \pm 0.06$ \\
& 0.4 & $4.33 \pm 0.04$ & $4.56^{*} \pm 0.06$ & $4.65^{*} \pm 0.07$ \\
& 0.6 & $4.76 \pm 0.13$ & $6.11^{*} \pm 0.03$ & $5.22^{*} \pm 0.08$ \\
& 0.8 & $5.9 \pm 0.05$ & $4.84^{*} \pm 0.09$ & $12.84^{\star} \pm 0.17$ \\
\hline
\end{tabular}

At the first three days, the ability of Mucor sp. and Rhizopus sp. to remove phenol had appeared slightly difference, because the longtime of acclimation period, where the organisms need a time to adapted for the use of phenol as a sole carbon source. The other reason for this way may be referred to sporulation stage which have a period of time to enter mycelium stage. After the first three days, the increased of phenol degradation by fungi was directly proportional with increase period of incubation. Then, bioremediation efficiency was slightly different. The reveal increased degradation efficiency can be explained by the availability of a carbon source which improves the fungi performances and growth and thereafter, the reduction of carbon source in the solution which is reflected as decrease or an inhibition in the bio-removal process (mortality of the cells) [27].

While the ability of fungi to degrade 1,3 dihydroxy benzene decreased when increased the concentration of it. the results of initial concentration effect of phenol within the range of 10-150 mg L-1. The uptake of phenol increased with the initial concentration up to $120 \mathrm{mg} \mathrm{L}-1$. Then uptake decreased as the initial phenol concentration was increased. The higher uptake at lower concentrations may be due to the presence of more available sites on the adsorbent than the number of phenol ions which are available in solution. The maximum uptake was determined at $120 \mathrm{mg} \mathrm{L}-1$ as $30 \mathrm{mg}$ g-1 [36].

\section{CONCLUSION}

The results indicated that a wide range of fungi species have the ability to degrade phenolic compounds. It can be say that the bio-removal is a wonderful technique for bioremediation of wastewater.

\section{COMPETING INTERESTS}

Authors have declared that no competing interests exist.

\section{REFERENCES}

1. Supriya MC, Deva N. Biodegradation of phenol by Aspergillus niger. IOSR. J. Phar. 2014;4(7):11-17.

2. Field JA, Lettinga G. Treatment and detoxification of aqueous spruce bark extracts by Aspergillus niger. Water Sci. Techn. 1991;24(3-4):127-137.

3. Borja R, Martin A, Maestro R, Luque M, Duran MM. Enhancement of the anaerobic digestion of wine distillery wastewater by the removal of phenolic inhibitors. Biores. Techn. 1993;45(2):99-104.

4. Brand D, Pandey A, Roussos S, Soccol CR. Biological detoxification of coffee husk by filamentous fungi using a solid state fermentation system. Enzyme Microb. Techn. 2000;27(1-2):127-133.

5. Lesage-Meessen L, Navarro D, Maunier S, Sigoillot JC, Lorquin J, Delattre M, Simon $\mathrm{JL}$, Asther M, Labat M. Simple phenolic 
content in olive oil residues as a function of extraction systems. Food Chem. 2001; 75(4):501-507.

6. Minhalma $\mathrm{M}$, de Pinho MN. Tannic membrane interactions on ultrafiltration of cork processing wastewaters. Separation and Purification Techn. 2001;22-23(1): 479-488.

7. Aggelis G, Ehaliotis C, Nerud F, Stoychev I, Lyberatos G, Zervakis GI. Evaluation of white-rot fungi for detoxification and decolorization of effluents from green olive debittering process. App. Microbio. Biotech. 2002;59(2-3):353-360.

8. Marrot B, Barrios-Martinez A, Moulin P, Roche N. Biodegradation of high phenol concentration by activated sludge in an immersed membrane bioreactor. Biochem. Engin. J. 2006;30:174-183.

9. Bodalo A, Gomez JL, Gomez M, Leon G, Hidalgo AM, Ruiz MA. Phenol removal from water by hybrid processes: Study of the membrane process step. Desalin. 2008;223:323-329.

10. Jayachandran VP, Kunhi AAM. Degradation of 3-chlorobenzoate and phenol singly and in mixture by a mixed culture of two orthopathway- following Pseudomonas strains. J. Indust. Microb. Biotech. 2008;5:120-122.

11. Przybulewska K, Wieczorek A, Nowak A, Pochrząszcz M. The isolation of microorganism capable of phenol degradation. Pol. J. Microb. 2006;55(1): 63-67.

12. Atlas RM, Bartha R. In Microbial Ecology: Fundamentals and applications. 4th Edition. Benjamin Cummings Science Publishing California; 1998.

13. Abd El-Zaher EHF, Mahmoud YAG, Aly MM. Effect of different concentrations of phenol on growth of some fungi isolated from contaminated soil. Afr. J. Biotechn. 2011;10(8):1384-1392.

14. Weir BA. Phenol treatment. Sci. Engin. 1991;51:338-344.

15. Udayasoorian C, Prabu PC. Biodegradation of phenols by ligninolytic fungus Trametes versicolor. J. Biol. Sci. 2005;5(6):824-827.

16. Celik GY, Aslim B, Beyatli Y. Enhanced crude oil biodegradation and rhamnolipid production by Pseudomonas stutzeri strain G11 in the presence of Tween-80 and Triton X-100. J. Envir. Biol. 2008;29:867870.
17. Laowansiri S, Vinitnantharat S, Chaiprasert $\mathrm{P}, \mathrm{Ha}$ SR. Anaerobic degradation kinetics of reactive dye with different carbon sources. J. Envir. Biol. 2008;29:309-314.

18. Santos VL, Andrea SM, Braga DT, Santoro MM. Phenol degradation by Aureobasidium pullulans FE13 isolated from industrial effluents. J. Hazard. Materials. 2009;16:1413-1420.

19. Shen J, Rui H, Yu H, Wang L, Zhang J, Sun X, Li J, Han W, Lu X. Biodegradation of 2,4,6-trinitrophenol (picric acid) in a biological aerated filter (BAF). Biores. Techn. 2009;11:1922-1930.

20. Mendonça E, Martins A, Anselmo AM. Biodegradation of natural phenolic compounds as single and mixed substrates by Fusarium flocciferum. Elect. J. Biotechn. 2004;7(1):30-37.

21. Atagana HI. Biodegradation of phenol, ocresol, m-cresol and p-cresol by indigenous soil fungi in soil contaminated with creosote. World J. Microb. Biotechn. 2004;20:845-849.

22. Sahebnazar Z, Shojaosadati SA, Mohammad TM, Nosrati M. Biodegradation of low-density polyethylene (LDPE) by isolated fungi in solid waste medium. Waste Management. 2010;30:396-401.

23. Watanabe T. Pictorial atlas of soil and seed fungi, morphologies of cultured fungi and key to species. CRC Press, Lewis Publishers Inc., USA; 1994.

24. Stoilova I, Krastanov A, Bui $H$. Biodegradation of mixed phenolic compounds by a microbial association of Aspergillus awamori and Thermoascus aurantiacus. Elect. J. Envir. Agri. Food Chem. 2008;7(12):2625-2633.

25. DOE (Department of the Environment). Analysis of Raw, potable and waste water. HMSO. London; 1972.

26. Folin O, Ciocalteau V. On tyrosine and tryptophane determinations in proteins. J. Biol. Chem. 1927;73:627-650.

27. Al-fawwaz AT, Jacob JH, Al-Wahishe TE. Bioremoval capacity of phenol by green micro-algal and fungal species isolated from dry environment. Intern. J. Sci. techn. Res. 2016;5(2):155-160.

28. Marker AFH. The use of acetone and methanol in the estimation of chlorophyll in the presence of phaeophytin. Freshwater Biol. 1972;2:361-385.

29. Metzner $H$, Rau $H$, Senger $H$. Untersuchungen Zur Synchronisierbarkeit 
einzelner Pigment-Mangel Mutanten Von Chlorella. Planta. 1965;65:186-94.

30. Powlowski JB, Dagley S. B-Ketoadipate pathway in Trichosporon cutaneum modified for methyl-substituted metabolites. J. Bacter. 1985;163:11261135.

31. Hinteregger C, Leitner R, Loidl M, Ferschl $A$, Streichsbier F. Degradation of phenol and phenolic compounds by Pseudomonas putida EKII. App. Microb. Biotechn. 1992; 37:252-259.

32. Muller $\mathrm{RH}$, Babel W. Biodegradative properties of alkaliphilic microorganisms from building materials of herbicide. Acta Biotechn. 1996;16:121-131.
33. Evans WC. The microbiological degradation of aromatic compounds. J. General Microb. 1963;32:177-184.

34. Hofrichter $M$, Scheibner $K$. Utilization of aromatic compounds by the Penicillium strain Bi 7/2. J. Basic Microb. 1993;33(4): 227-232.

35. Leitão A. Potential of Penicillium Species in the Bioremediation Field. Inter. J. Envir. Res. Public Health. 2009;6(4):1393-1417.

36. Moyo M, Mutare E, Chigondo $F$, Nyamunda BC. Removal of phenol from aqueous solution by adsorption on yeast, Saccharomyces cerevisiae. Inter. J. Res. Rev. App. Sci. 2012;11(3):486-494.

(c) 2018 Shebany et al.; This is an Open Access article distributed under the terms of the Creative Commons Attribution License (http://creativecommons.org/licenses/by/4.0), which permits unrestricted use, distribution, and reproduction in any medium, provided the original work is properly cited.

Peer-review history:

The peer review history for this paper can be accessed here: http://www.sdiarticle3.com/review-history/47494 